CLINICAL IMAGES

\title{
A Broken Leg in the Bugs
}

In September 2015 the British Army Mountaineering Association organized a climbing expedition to Bugaboo Provincial Park, British Columbia, Canada (Figure 1). While descending the South Ridge on Brenta Spire, one member of the climbing party sustained a broken leg. Disaster was averted by taping up the leg with zinc oxide tape. Miraculously, the climber managed to descend from the mountain without further assistance. How was this possible?

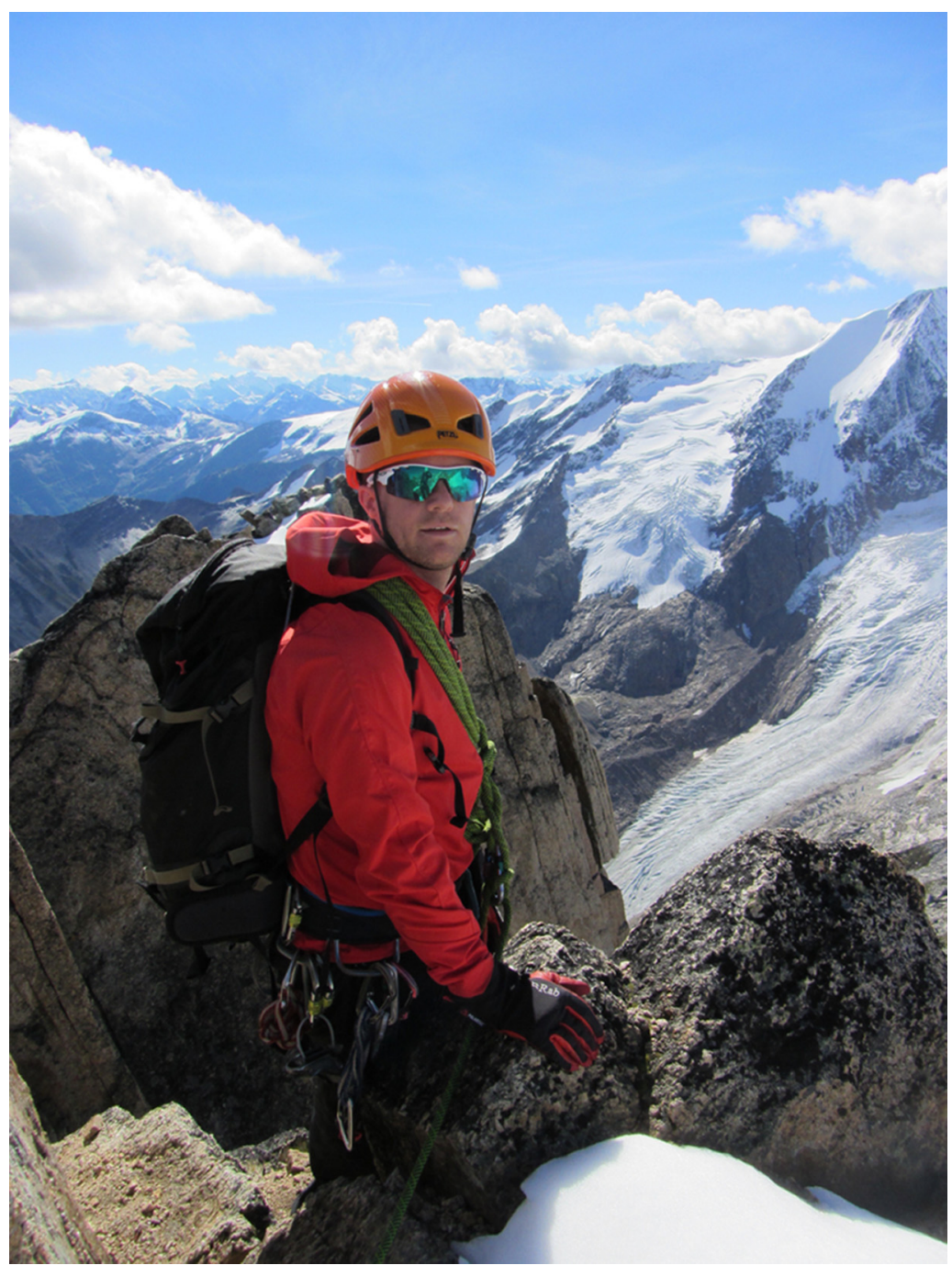

Figure 1. WO2 Barry Whale near the summit of Brenta Spire. 
The climber had broken his prosthetic limb!

While ascending the mountain, the climber had noticed increasing movement between the pylon of the prosthesis and the prosthetic foot. At the summit, he attempted to repair a loose hex bolt in the artificial ankle, but having uncharacteristically forgotten to bring the correct size hex key, he was only able to tighten it finger-tight. On descent, the prosthesis loosened to the point of failure, thankfully while on easy ground (Figure 2). The expedition doctor effected a repair of the leg from the contents of his medical kit (Figure 3). This repair held firm for the remaining 3-hour walk/rappel back to the campsite.

Lessons learned from this experience are, first, zinc oxide tape serves as a very useful repair material for

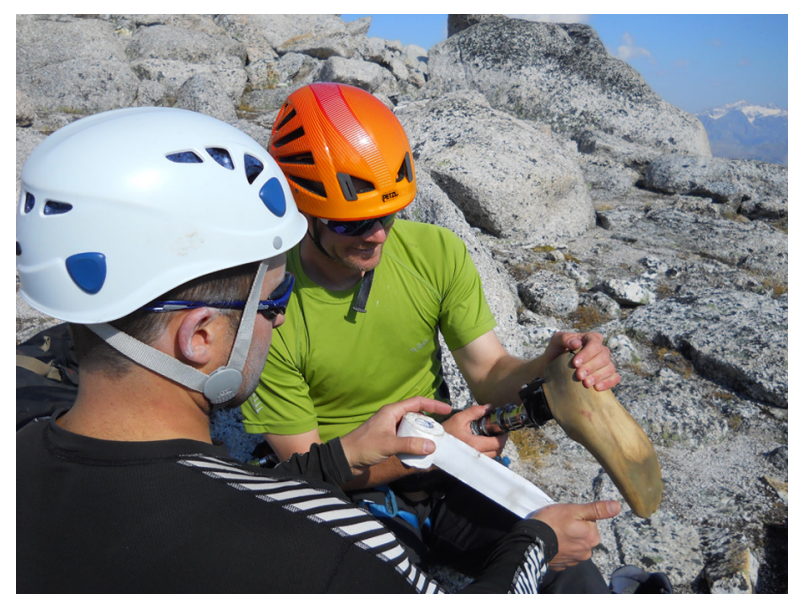

Figure 2. The author and $\mathrm{WO} 2$ Whale fixing the broken prosthetic limb.

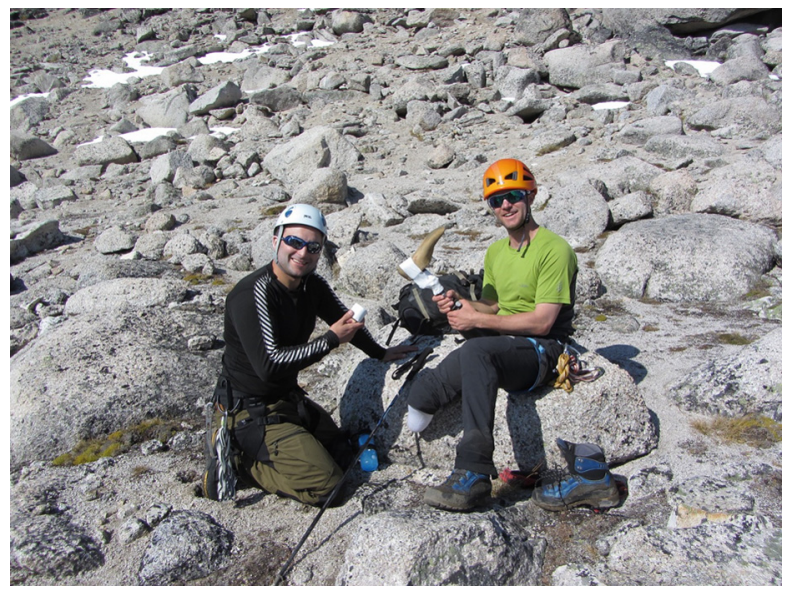

Figure 3. Repair complete.

prosthetic limbs in the mountain environment and, second, if a climber has a prosthetic limb with hex bolts, it is important to ensure that bolts are kept tight and that the correct size hex key is carried within the group.

\section{Acknowledgments}

The author would like to thank WO2 Barry Whale for his permission to publish this article relating to his fractured prosthesis.

Alexander J. Martin-Bates, MBBS, MRCGP Royal Army Medical Corps, Medical Centre, Dhekelia, United Kingdom 